Original Article

\title{
MICROBIAL EXTRACTION OF CHITIN AND CHITOSAN FROM PLEUROTUS SPP, ITS CHARACTERIZATION AND ANTIMICROBIAL ACTIVITY
}

\author{
JESTEENA JOHNEY1, KANNAN EAGAPPAN², R. R. RAGUNATHAN ${ }^{1}$ \\ ${ }^{1}$ Centre for Bioscience and Nanoscience Research, Eachanari, Coimbatore-21, Tamilnadu. India, ${ }^{2}$ Department of Clinical Nutrition and \\ Dietetics, PSG College of Arts and Science, Coimbatore, Tamilnadu, India \\ Email: dtkannan@gmail.com \\ Received: 07 Oct 2016, Revised and Accepted: 10 Dec 2016
}

\begin{abstract}
Objective: The aim of the present work was to extract the chitin and chitosan from two species of Pleurotus, its characterization and its antimicrobial activity against bacteria and fungi.

Methods: The fungi were grown in MGYP medium for $15 \mathrm{~d}$. The chitin and chitosan were extracted using the alkaline method and various biochemical methods and compared with commercial chitin and chitosan. The FTIR and SEM were also performed. Antimicrobial activity was performed using well diffusion method.

Results: The maximum yield of mycelia and the chitin and chitosan were obtained on $12^{\text {th }}$ day of incubation. $P$. folrida gave maximum yield $(201.3$ mg/l of chitin and $65.61 \mathrm{mg} / \mathrm{l}$ of chitosan). Fourier Transform Infrared spectroscopy comparing the results obtained with results for commercial chitin and chitosan. Our results showed that chitin and chitosan obtained from Pleurotus spp. had a significant similitude with commercial. SEM image also carried out to study the surface morphology. The fungal chitin and chitosan had more antimicrobial activity against the gram+ve, gram-ve and the various fungus.

Conclusion: In the present study the chitin and chitosan were extracted from the Pleurotus spp. (P. florida and $P$. eous). The yield was maximum in $P$. florida after $12^{\text {th }}$ day of fermentation. The FTIR and SEM also confirmed the chitin and chitosan. The extracted chitin and chitosan were subjected to antimicrobial activity, and it was found the extracted chitin and chitosan were active against the bacteria and fungi. Our findings suggest that the Pleurotus spp. are the potential candidate to produce eco-friendly chitin and chitosan in the development of drugs, artificial bone and raw material for the food industries in the near future.
\end{abstract}

Keywords: Chitin, Chitosan, FTIR, SEM, Pleurotus spp., Antibacterial activity

(C) 2016 The Authors. Published by Innovare Academic Sciences Pvt Ltd. This is an open access article under the CC BY license (http://creativecommons.org/licenses/by/4.0/) DOI: http://dx.doi.org/10.22159/ijcpr.2017v9i1.16623

\section{INTRODUCTION}

The name 'chitin' is derived from the Greek word 'chiton', meaning a coat of mail. and was apparently First used by Bradconnot in 1811 [1] and [2]. Chitin is a polysaccharide, made of $\mathrm{N}$-acetyl-Dglucosamine units connected by $\beta(\mapsto 4)$ linkage and it is a second most abundant natural biopolymer after cellulose, with this difference that in chitosan one hydroxyl group on each monomer has substituted with an acetylamine group. The chemical structure of chitin is similar to that of cellulose with 2-acetamido-2-deoxy-b-dglucose (NAG) monomers attached $\beta$ (1-4) linkages [3].

Chitin is a hard, inelastic, and white polysaccharide found in the exoskeleton of insects, crabs, shrimps and lobsters, in the internal structure of other invertebrates such as prawns and insects, as well as, on the cellular wall of fungi and yeasts. It is the second most abundant biopolymer after cellulose [4]. Chitin is an n-acetyl-d-glucosamine linear polymer joined by b (1-4) glycosidic linkage: (1-4, 2-acetamide2-deoxy-b-D-glucan) and there are three different polymeric forms $a, b$ and c [5]. It has relevant properties including antimicrobial, antifungal, and antiviral activities; it is non-toxic, biocompatible, biodegradable, emulsifying, grease-absorbent, the adsorbent of contaminating metals, and fibrogenic; therefore, it is considered that chitosan has wideranging applications in various industrial fields [6].

Chitosan is the deacetylated form of chitin, which, unlike chitin, is soluble in acidic solutions Chitosan $(1,4) 2$-amino-2-d-glucose is a cationic biopolymer produced by alkaline $\mathrm{N}$-deacetylation of chitin, which is the main component of the shells of crab, shrimp, krill and other crustaceans [3].

Chitin and chitosan are the biopolymers that have received much research interests due to their numerous potential applications in agriculture, food industry, biomedicine, paper making and textile industry. The most common source of chitin and chitosan is the crustaceous shell; however, mushrooms are an alternative source for isolating these biopolymers because their cellular wall has a high content of chitin, which may be transformed into chitosan through a deacetylation reaction [7].

Chitosan is a polymer derived from chitin and is used in applications from health care to agriculture to dyes for fabrics. There are even medical applications. Chitosan itself is the major source of the nutritional supplement glucosamine. Chitosan is, at the $\mathrm{pH}$ of the gastrointestinal tract, a positively charged polymer and can bind to negatively charged substances. Chitosan might bind to some dietary lipids. It may also bind to the fat-soluble vitamins $\mathrm{A}, \mathrm{D}, \mathrm{E}$, and $\mathrm{K}$, as well as flavonoids, carotenoids and some minerals such as zinc, found in foods [8].

Production of chitin and chitosan from fungal mycelium has recently received increased attention due to significant advantages. For example, while crustacean waste supplies are limited by seasons and sites of fishing industry, fungal mycelium can be obtained by convenient fermentation process that does not have geographic or seasonal limitations, fungal mycelia have lower level of inorganic materials compared to crustacean wastes, and thus no demineralization treatment is required during the processing, crustacean chitin and chitosan may vary in the physicochemical properties, while fungal chitin and chitosan have relatively consistent properties because of the controlled fermentation conditions, fungal chitin and chitosan are apparently more effective in inducing the plant immune response and are potentially more suitable for agricultural applications [9].

Many fungal species, including Absidiaglauca, Absidiacoerulea, Aspergillus niger, Mucorrouxii, Gongronellabutleri, Phycomyces- 
blakesleeanus, Absidiablakesleeana, Rhizopusoryzae, Trichoderma reesei and Lentinusedodes have been investigated for the production of chitin and chitosan. Among all investigated species, the most commonly researched one is M. rouxii [10], and quantities of chitin and chitosan in its mycelia can reach $35 \%$ of cell wall dry weight. Extraction process from fungal sources is similar to industrially utilised except that no demineralization treatment is required due to low mineral content in fungal mycelia fungal cell walls are composed of neutral polysaccharides, chitin, chitosan and glycoproteins with minor amounts of galactosamine polymers, polyuronides, melanin and lipids [11].

Recently increasing attention has been paid to develop and test coating with antimicrobial properties in order to improve food safety and shelf life. Active biomolecule such as chitosan and its derivatives have a significant role in a food product. Chitosan has a great potential for a wide range of application due to its biodegradability, biocompatibility, antimicrobial activity, nontoxicity, and versatile chemical and physiological properties [12]. On a commercial scale, chitin and chitosan were extracted from the exoskeleton of crustaceans employing various chemical process resulted in pollution and other environmental problems. To overcome this, recent advances in fermentation technology have attracted the researchers to extract the chitin and chitosan from various fungal mycelium. [13] extracted chitin and chitosan from Agaricus Spp, Pleurotus Spp. and Ganoderma Spp. [14]. Produced chitosan from fungal mycelium by submerged fermentation with the ecologically more balanced process. They used different fungal strains. The antimicrobial activity of chitin, chitosan and their derivatives against different groups of microorganisms, such as bacteria, yeast, and fungi, has received considerable attention in recent years $[15,16]$ extracted the chitin and chitosan from Aspergillusterrus CBNRKR KF529976 using a different medium.

The preparation and characterization of chitosan and its biomedical applications are still limited. The present study focused on an ecofriendly method of extraction of chitin and chitosan from two edible fungi, Pleurotusflorioda and P. eous. The extracted chitin and chitosan were characterised and its antimicrobial studies were also evaluated.

\section{MATERIALS AND METHODS}

\section{Chemicals}

All the chemicals and reagents used were of AR grade from Hi-Media (Mumbai).

\section{Microorganism}

The culture of Pleurotusflorida and P. eous were grown at $25^{\circ} \mathrm{C}$ for 7 $\mathrm{d}$ on potato dextrose agar (PDA), and was periodically transferred onto a new PDA medium. The strain was maintained at $4{ }^{\circ} \mathrm{C}$ and this was used for further studies.

\section{Production medium}

Actively growing mycelia were obtained from a newly prepared PDA agar plate culture after being incubated for $7 \mathrm{~d}$ at $25^{\circ} \mathrm{C}$. The preinoculums were prepared as follows about $1 \mathrm{~cm} \times 1 \mathrm{~cm}$ of mycelia was inoculated into a $250 \mathrm{ml}$ Erlenmeyer flask, which contained 50 $\mathrm{ml}$ of MGYP medium (meat extract $2 \%$; glucose $1.5 \%$; yeast extract$0.3 \%$ and peptone $0.5 \%$ ). The inoculated Erlenmeyer flask was incubated at $28^{\circ} \mathrm{C}$ for $15 \mathrm{~d}$, without any disturbance.

After $15 \mathrm{~d}$ of incubation, the growed fungal mycelium of Pleurotus florida and P. you were separately filtered through What Man No.1 filter paper. The mycelium mat was washed with sterilised distilled water until getting a clear filtrate. The mat was dried at $60^{\circ} \mathrm{C}$ to get a constant weight for the extraction of chitin and chitosan.

\section{Chitin extraction}

Chitin was extracted from the modified protocol of [17]. The dried fungal cell mass was finely homogenised and subjected to alkali treatments to extract soluble alkali material like glucan and protein, present in fungal biomass. Fungal mycelia mat was subjected to alkaline treatment with $1 \mathrm{M} \mathrm{NaOH}$ in the ratio of $1: 30(\mathrm{v} / \mathrm{v})$. Then the mixture was mixed, and this was incubated in $45^{\circ} \mathrm{C}$ for $2 \mathrm{~h}$. Then this suspension was centrifuged at $8000 \mathrm{rpm}$ for $10 \mathrm{~min}$, and washed with deionized water. Decolorization was done with $10 \mathrm{~g} \mathrm{~L}^{-1}$ potassium permanganate for $90 \mathrm{~min}$, and then this was treated with $10 \mathrm{gL}^{-1}$ oxalic acid for $1 \mathrm{hr}$. After decolorization technique again centrifuged and washed until getting neutral $\mathrm{pH}$. This was dried at $45^{\circ} \mathrm{C}$ for $12 \mathrm{~h}$. The amount of chitin was determined by a dry weight method.

\section{Chitosan extraction modified protocol of [18]}

After the cultivation of fungus, the mycelia mat were separated, and this was first treated with $1 \mathrm{~N} \mathrm{NaOH}$ solution $(\mathrm{v} / \mathrm{W})$ and this was sterilised under autoclave at $121{ }^{\circ} \mathrm{C}$ for $20 \mathrm{~min}$. After sterilisation, the mixture was centrifuged at 10,000 rpm for $8 \mathrm{~min}$, and this was washed with deionised water to get neutral $\mathrm{pH}$ and kept in $40^{\circ} \mathrm{C}$ for drying. To this $2 \%$ acetic acid were added (v/v) and kept at $95^{\circ} \mathrm{C}$ for $5 \mathrm{~h}$, then this was centrifuged at $10,000 \mathrm{rpm}$ for $10 \mathrm{~min}$ and the supernatant was collected and added $2 \mathrm{~N} \mathrm{NaOH}$ solution, mixed well and centrifuged. Washing was done with deionized water and ethanol, finally with acetone to get neutral $\mathrm{pH}$. Then these were incubated at $45^{\circ} \mathrm{C}$ to get the constant weight of chitosan.

\section{Characterization of chitin and chitosan}

\section{FTIR}

The structure of extracted mycelia chitin and chitosan was confirmed by infrared spectroscopy using $\mathrm{KBr}$ pellet methodin FTIR (Shimadzu FTIR-8200, Japan). In FTIR spectra were recorded in the middle infrared (4000 cm-1 to $400 \mathrm{~cm}-1)$ with a resolution of 4 $\mathrm{cm}-1$ in the absorbance mode for 16 scans at room temperature. The mycelial chitosan samples were prepared by grinding the dry mycelial chitosan powder with powdered $\mathrm{KBr}$, in the ratio of $1: 5$ (sample: $\mathrm{KBr}$ ) and then compressed to form $\mathrm{KBr}$ pellet and subjected to FTIR analysis.

\section{SEM}

The extracted chitin and chitosan samples were examined and photographed in SEM using ICON ANALYTICAL, FEI with Model QUANTA 200 instruments.

\section{Antimicrobial assay}

The agar well diffusion method was used for the antibacterial assay. Petri plates were prepared by pouring $20 \mathrm{ml}$ of Muller Hinton Agar medium and allowed to solidify. Plates were solidified and $20 \mu \mathrm{l}$ of $24 \mathrm{~h}$ old bacterial culture E. coli, S. aureus, P. aeruginosa, K. pneumonia and B. Subtilis were poured and uniformly spread. The excess inoculum was drained away, and the inoculum was allowed to dry for $5 \mathrm{~min}$. Agar well of $5 \mathrm{~mm}$ in diameter was prepared with the help of a sterilised stainless cork borer. The wells were labelled appropriately and to each well were loaded with $20 \mu$ lof extract. The plates were incubated at $37^{\circ} \mathrm{C}$ for $24 \mathrm{~h}$. Antibacterial activity was evaluated by measuring the diameter of zones of inhibition against the tested bacteria.

PDA agar medium was prepared from commercially available dehydrated base according to the manufacturer instructions. The wells were made using cork borer on PDA agar plate. The borer was deeped into the alcohol for sterilisation and then was used to make wells. Wells with $10-\mathrm{mm}$ diameter were punched in the agar and filled with $20 \mu \mathrm{l}$ of the fungal spores. The plates were incubated at room temperature and the zone of inhibition were calculated.

\section{RESULTS AND DISCUSSION}

The synthesis of chitosan involves various chemical steps such as preparation of the chitin from the mycelial mat of Pleurotus spp which will be the initiation of the chitosan synthesis with the removal of the proteins in the shells followed by demineralization for the removal of the carbon and other salts present in the crude form which will be preceded by the deacetylation of the chitin that would result in chitosan. The regular chitosan is obtained by following the above steps, but a polymer of pharmaceutical grade has to fall in the region of its predetermined quality aspects, and usually commercial chitins are prepared by the first step of deproteinization followed by a second step of demineralization. 


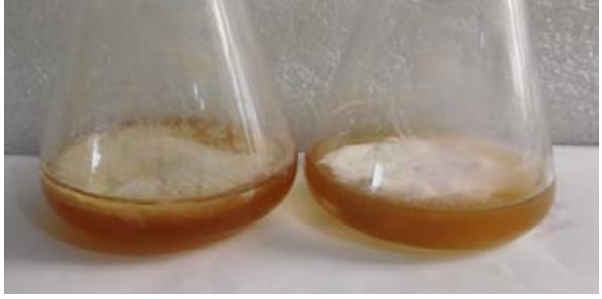

Fig. 1: Growth and mycelial mat formation of Pleurotus florida and Pleurotuseous in MGYP medium after $15 \mathrm{~d}$ of incubation

The fungal growth was monitored for $15 \mathrm{~d}$. The growth rate of the different fungal species was varied and shown in table 1 . The greatest biomass, chitin and chitosan were harvested in the case of $P$. Florida and the lowest in the case of P. eous. [19] obtained chitosan from different fungus (Aspergillusniger TISTR3245, Rhizopusoryzae TISTR3189, Lentinuse dodes no. 1, Pleurotus sajocaju no. 2, Zygosaccharomycesrouxii TISTR5058 and, Candida albicans TISTR5239. They carried out cultures fungus during different periods among 15-21 d, and then, they evaluated biomass and chitosan production yield. Rhizopusoryzae TISTR3245 was shown to give a maximal yield of chitosan at $138 \mathrm{mg}$ g-1 dry weight.

In the present study, the maximum yield of the chitin and chitosan was obtained on $12^{\text {th }}$ day of incubation byP. Florida $(201.3 \mathrm{mg} / \mathrm{g})$ followed by the P. eous $(145.65 \mathrm{mg} / \mathrm{g})$.[20] produced chitosan from Rhizopusoryzae PAS 17 in low-cost non-sterile conditions revealed the increment of chitosan and biomass yields of 14.45 and 8.58 folds from its an optimised condition, respectively [14].

Table 1: Biomass and yield of chitin and chitosan extracted from Pleurotus. spp

\begin{tabular}{lllll}
\hline \multirow{2}{*}{ Day } & Yield of Biomass (g/l dry wt) & & Chitin (mg/l) & Chitosan (mg/l) \\
\cline { 2 - 5 } & Pleurotus florida & Pleurotus eous & Pleurotus florida & Pleurotus eous \\
\hline 3 & 1.2 & 0.89 & 25.63 & 0.124 \\
6 & 4.89 & 3.14 & 55.32 & 0.418 \\
9 & 8.52 & 6.58 & 75.62 & 0.602 \\
12 & 10.52 & 8.96 & 201.3 & 145.65 \\
15 & 9.56 & 8.24 & 65.61 & 45.23 \\
\hline
\end{tabular}

Used different Zygomycetes for the production of mycelial chitosan and Absidiabutleri NCIM 977 was found to produce the highest mycelial chitosan which is identical to our investigation. [21] extracted chitosan from $A$. niger under solid state fermentation after $12 \mathrm{~d}$ of fermentation with the yield at $10.9 \mathrm{~g} / \mathrm{kg}$ of urea as substrate and $17.05 \mathrm{~g} / \mathrm{kg}$ of chitin using soyabean residue.

[13] chitosan extracted from $15 \mathrm{~d}$ old biomass of Agaricuss spp pleurotus spp, ganoderma spp contain the yield of $0.944 \mathrm{mg} / \mathrm{g}$ of substraate. [22] extracted high yield at chitosan $29.7 \%$ using $P$. waksmanii. Production of chitosan from fungi of A. niger, R. oryzae, $L$. edodes and P. sajorcaju, (21\%) [23].

\section{FTIR}

The FTIR spectrum was measured in transparent potassium bromide pellets with Shimadzu FTIR-8200, Japan Spectrum one FT-IR spectrometer to identify the structural groups in the raw material. The raw material was characterised by FT-IR in the middle region, in the range of 4000-400 cm-1. For comparison, commercial chitosan from shrimp shells (Hi Media, Mumbai) was used. (fig. 2 to. 4).

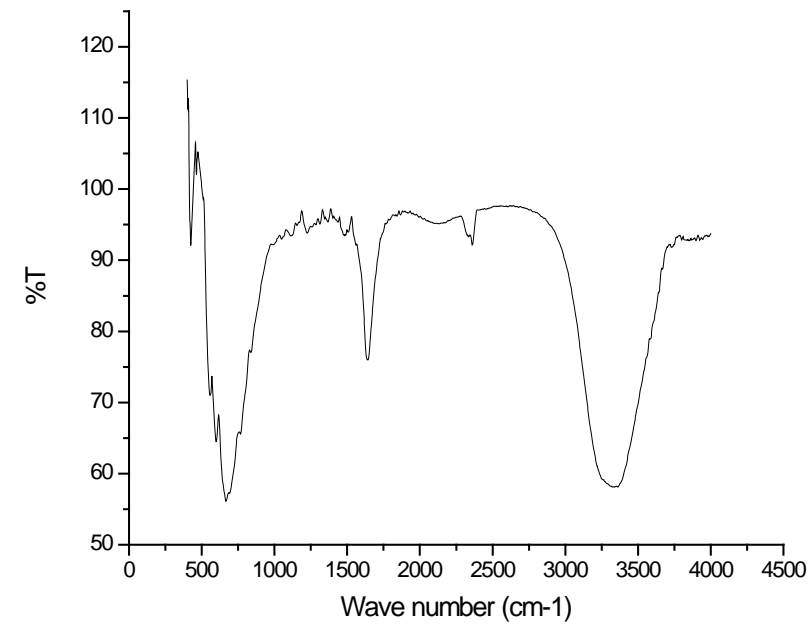

Fig. 2: Standard-chitin

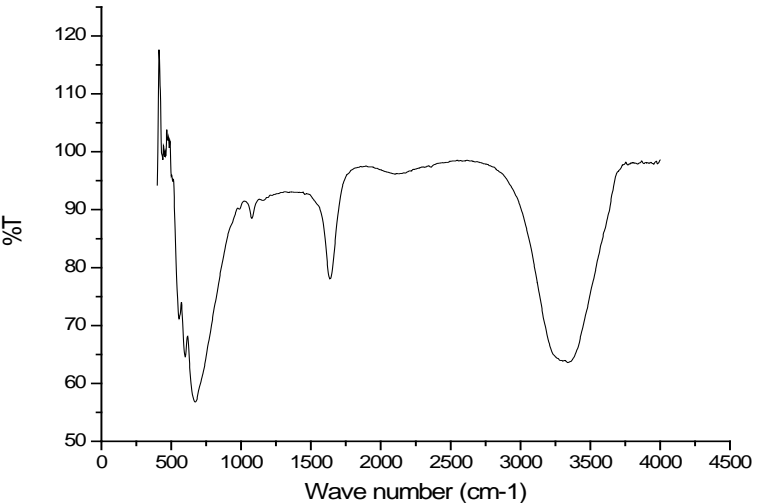

Fig. 3: Chitin extracted from P. florida

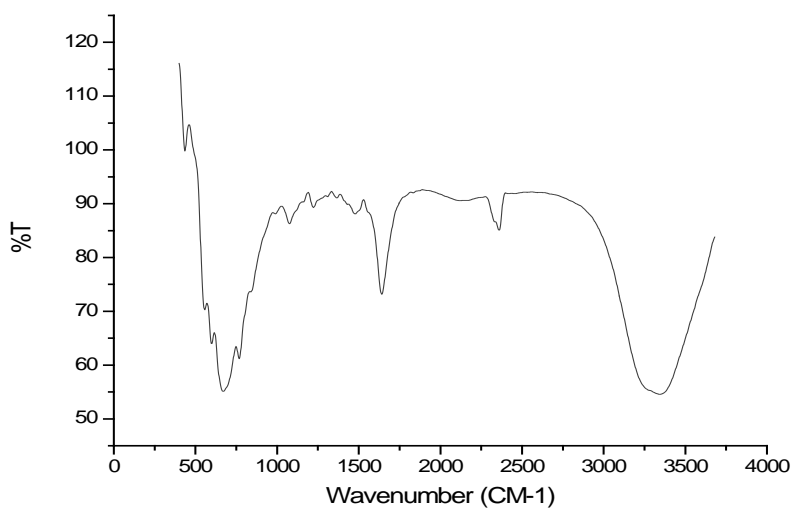

Fig. 4: Chitin extracted from P. euos

In our study, the infrared spectra of the chitins extracted from $P$. florida and $P$. eous were characterized by three significant amide bands at 1654,1617 and $1550 \mathrm{~cm}-1$, which corresponded to the $\mathrm{C} 0$ secondary amide stretch (Amide I), C 0 secondary amide stretch (AmideI), and $\mathrm{N} \mathrm{H}$ bend and $\mathrm{C} \mathrm{N}$ stretch(Amide II), respectively (fig. 2). The absorbance bands of $3268,2930,2878,1563$, and $1418 \mathrm{~cm}-1$ 
indicated the $\mathrm{N}-\mathrm{H}$ stretching, Symmetric $\mathrm{CH} 3$ stretching and asymmetric $\mathrm{CH} 2$ stretching, $\mathrm{CH}$ stretching, $\mathrm{C}=0$ stretching in secondary amide (amide I) and $\mathrm{C}-\mathrm{N}$-stretching in secondary amide (amide II), respectively [24].

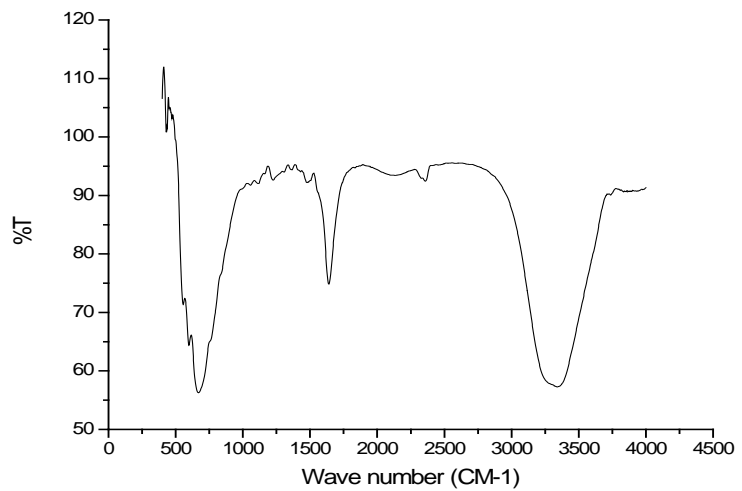

Fig. 5: Standard chitosan

In the present study also the same absorbance bands were observed at $3283,2921,2865,1643,1552,1421,1022,893$ and $752 \mathrm{~cm}-1$ which confirm the structure of chitosan of $P$. florida and $P$. euous. Several bands have been proposed as internal reference bands of chitosan: the $\mathrm{OH}$ stretching band at $3450 \mathrm{~cm}-1$; the $\mathrm{C}-\mathrm{H}$ stretching bands within $2870-2880 \mathrm{~cm}-1$; the skeletal vibrations involving the C-O-C stretching band at 1030-1070 $\mathrm{cm}-1$; the- $\mathrm{CH} 2$ bending centered at $1420 \mathrm{~cm}-1$; the anti-symmetric stretching of the C-O-C bridge around $1160 \mathrm{~cm}-1 ; 1315-1320 \mathrm{~cm}-1$ (amide III band); 1620-1630 $\mathrm{cm}-1$ (-NH bending of NH2); and $890-900 \mathrm{~cm}-1$ (C-O-C bridge as well as glucosidic linkage) [25 and 26].

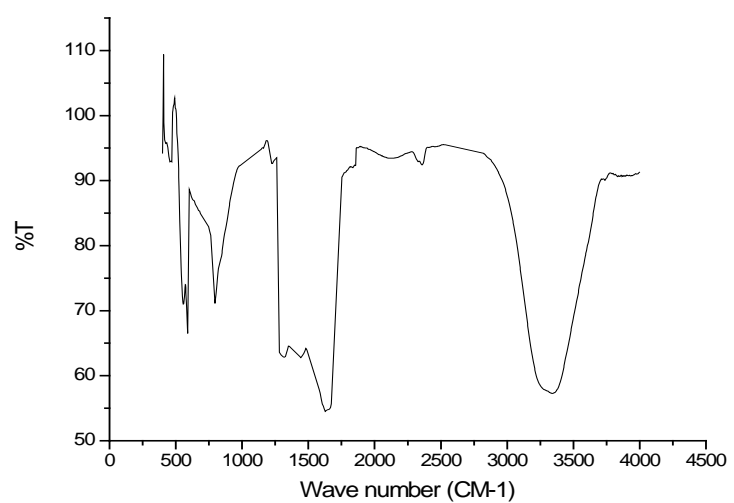

Fig. 6: Chitosan extracted from $P$. florida

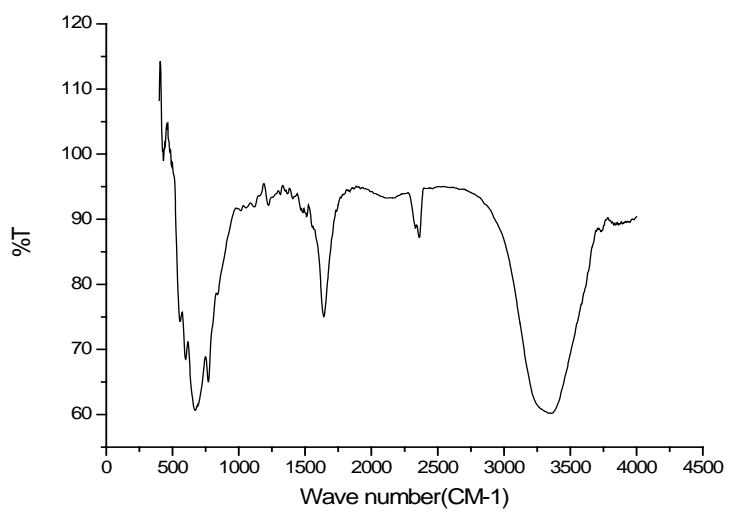

Fig. 7: Chitosan extracted from P. euos
FTIR analysis shows that chitin and chitosan represent the bands according to the report of [24] and [9], compared with standard chitin and chitosan.

\section{SEM}

SEM analysis showed that chitosan had a long thin crystal structure on a smooth surface. This was in accordance with previous data [27]. Nonhomogenous and non-smooth surface structure of chitosan were also reported by. It is well documented in the literature that the surface morphology of chitin differs depending on insect species, gender and growth stage. [28] Observed that chitins extracted from adult and nymph grasshoppers (Dociostaurusmaroccanus) consisted of long nanofibers with many big nanopores. A very uniform structure with a lamellar organisation and less dense structure was observed in the present study (fig. 8 and 9).

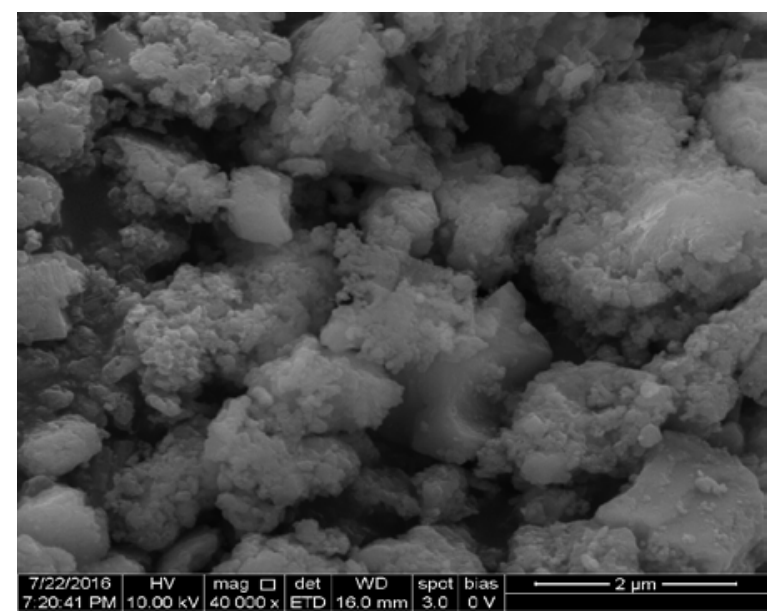

Fig. 8: SEM image of chitin

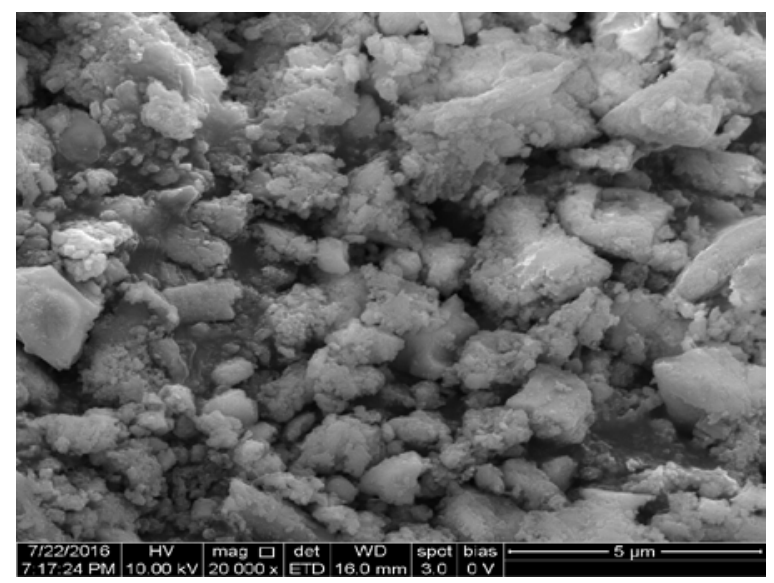

Fig. 9: SEM image of chitosan

\section{Antimicrobial activity}

The antimicrobial activity of chitin, chitosan, and their derivatives against different groups of microorganisms, such as bacteria, yeast, and fungi, has received considerable attention in recent years. Two main mechanisms have been suggested as the cause of the inhibition of microbial cells by chitosan. The interaction with anionic groups on the cell surface, due to its polycationic nature, causes the formation of an impermeable layer around the cell, which prevents the transport of essential solutes. It has been demonstrated by electron microscopy that the site of action is the outer membrane of gram-negative bacteria [29]. In our present study, the extracted chitin and chitosan showed encouraging results against bacterial and fungal pathogens with maximum inhibitory activity against the fungal pathogens (fig. 10 to 13 ). 


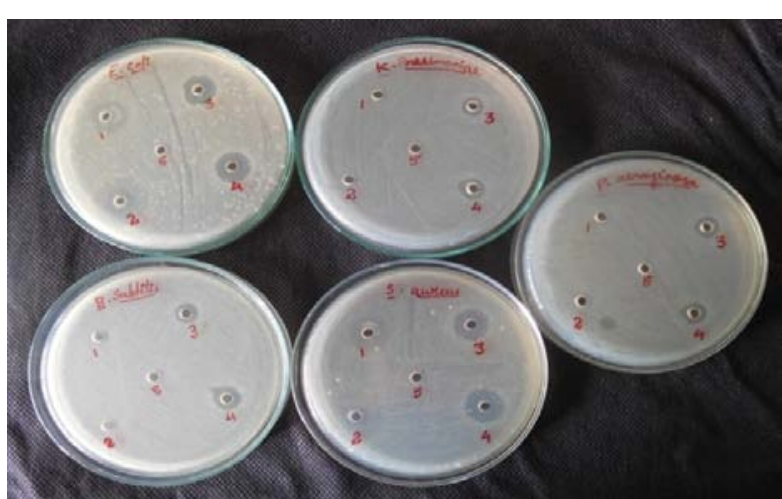

Fig. 10: Antibacterial activity of extracted chitin and chitosan with commercially available chitin and chitosan against pathogens. (1-Commercial chitin; 2-Commercial chitosan; 3 Extracted chitin; 4 Extracted chitosan; 5 Control (DMSO)

In vitro antibacterial screening of chitosan and water soluble chitosan from Pleusrots spp. against selected clinical isolates were performed and zone of inhibition were given in graph (fig. 6 and7). The highest zone of inhibition was observed in E. coli, S. sureus, $B$. subtilis followed by $P$. aeuroginosa,K pneumonia when compared with the commercial chitin and chitosan. The chitin and chitosan also exhibited the antifungal activity against $A$. niger $(5 \mathrm{~mm}), A$. flavus $(5 \mathrm{~mm})$ followed by the $F$. solani $(5 \mathrm{~mm})$. [30] reported that chitin and chitosan from shrimp shell waste have antibacterial activity against E. coli and $S$. aureu.

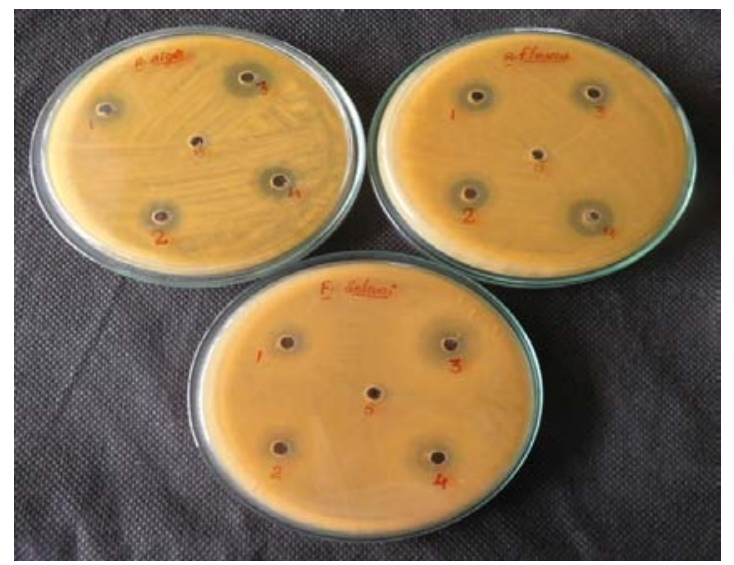

Fig. 11: Antifungal activity of extracted chitin and chitosan with commercially available chitin and chitosan against pathogens.

(1-Commercial chitin; 2-Commercial chitosan; 3 Extracted chitin; 4 Extracted chitosan; 5 Control (DMSO)

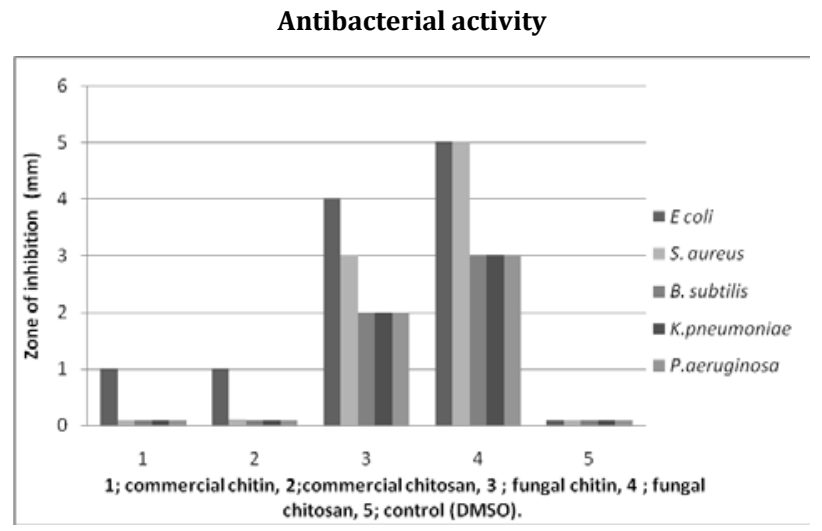

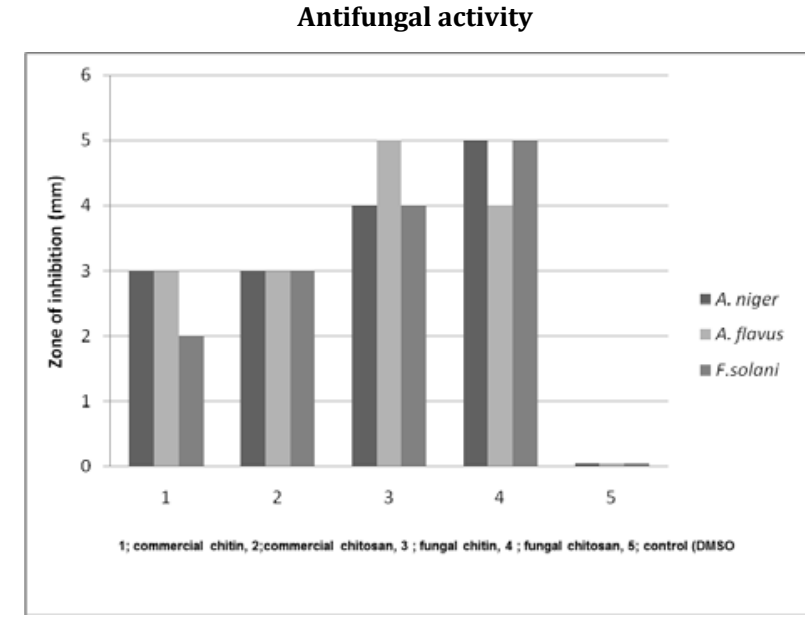

\section{ACKNOWLEDGEMENT}

The authors thank the Research and Development Centre of Bharathiar University, Coimbatore, Tamilnadu, India for their support in this research work.

\section{CONFLICT OF INTERESTS}

We declare that we have no conflict of interest

\section{REFERENCES}

1. Lower SE. Polymers from the sea chitin and chitosan. Manuf Chem 1984;55:73-5.

2. Skaugrud O, Sargent G. Chitin and chitosan: crustacean biopolymers with potential application. International By-products Conference, Anchorage, Alaska; 1990. p. 61-72.

3. Fereido on Shahidi, Janak Kamil Vidana Arachchi, You-Jin Jeon. Food applications of chitin and chitosan. Trends Food Sci Technol 1999;10:37-51.

4. Wan ACA, Tai BCU. CHITIN-A promising biomaterial for tissue engineering and stem cell technologies. Biotechnol Adv 2013;31:1776-85.

5. Dutta PK, Ravikumar MNV, Dutta J. Chitin and chitosan for versatile applications. Polym 2002;42:307-54.

6. Caprile MD. Obtencion y utilizacion de quitina y quitosano a partir de desechos de crusta'ceos. Congreso Mundial ISW: Haciaunsistema integral de residuossolidosurbanos, Argentina; 2005.

7. Natali Mesa Ospina, Sandra Patricia Ospina Alvarez, Diana Marcela Escobar Sierra, Diego Fernando Rojas Vahos, Paola Andrea Zapata Ocampo, Claudia Patricia Ossa Orozco. Isolation of chitosan from Ganodermalucidum mushroom for biomedical applications. J Mater Sci: Mater Med 2015;26:135.

8. HK No, Meyers SP, W Prinyawiwatkul, Z Xu. Applications of chitosan for improvement of quality and shelf life of foods: a review. J Food Sci 2007;72:R87-100.

9. Teng WL, Khor E, Tan TK, Lim LY, Tan SL. Concurrent production of chitin from shrimp shells and fungi. Carbohydr Res 2001;332:305-16.

10. Chatterjee S, Adhya M, M Guha, AK Chatterjee. BP chitosan from Mucorrauxii spp. production and physio-chemical charectorisation. Process biochem; 2004.

11. Percot A, Viton C, Domard A. Optimization of chitin extraction from shrimp shells. Biomacromolecules 2003;4:12-8.

12. Dutta PK, Tripath S, Mehrotra GK, Dutta J. Perspective of chitosan-based antimicrobial films in food applications. Food Chem 2009;114:1173-82.

13. Kannan M, Nesakumari M, Rajarathinam K, Singh AJAR. Production and characterization of mushroom chitosan under solid-state fermentation conditions. Adv Biol Res 2010;4:10-3.

14. Vaingankar PN, Juvekar AR. Fermentative production of mycelial chitosan from zygomycetes: media optimisation and physicochemical characterization. Adv Biosci Biotechnol 2014;5:940-56. 
15. Yang $\mathrm{N}$, Li W. Facile one-pot synthesis of chitosan oligosaccharide/silver nanocomposites and their antimicrobial properties. Mater Lett 2014;132:145-8.

16. Krishnaveni B, Ragunathan R. Extraction and characterization of Chitin and Chitosan from Aspergillusterreusspp. synthesis of their bionanocomposites andstudy of their productive applications. J Chem Pharm Res 2015;7:115-32.

17. Sandra Patricia Ospina-Alvarez, David Alexander Ramirez Cadavid, Diana Marcela Escobar Sierra, Claudia Patricia Ossa Orozco, Diego Fernando Rojas Vahos, Paola Zapata Ocampo, et al. Comparison of extraction method of chitin from Ganodermalucidum mushroom obtained in submerged culture. Hindawi publishing corporation BioMed Res Int 2014:7. http://dx.doi.org/10.1155/2014/169071

18. $\mathrm{Hu} \mathrm{KJ}, \mathrm{Hu} \mathrm{JL}, \mathrm{Ho} \mathrm{KP}$, Yeunj KW. Screening of fungi for chitosan producers, and copper adsorption capacity of fungal chitosan and chitosanaceous materials. Carbohydratepolymers 2004;58:45-52.

19. Pochanavanich P, Suntornsuk W. Fungal chitosan production and its characterization. Department of Microbiology, King Mongkut's the University of Technology. Thon buri, Thailand. Appl Microbiol 2002;35:17-21.

20. Ozden Canli Tasara, Serkan Erdalb, Mesut Taskin. Chitosan production by psychrotolerant Rhizopusoryzaein non-sterile open fermentation conditions. Int J Biol Macromol 2016;89:428-33.

21. Maghsoodi V, Yaghmaie S. Influence of different nitrogen sources on the amount of chitosan production by Aspergillusniger in solid state fermentation. Iran J Chem Chem Eng 2008;27:47-52.

22. Mohammad Ali Ebrahimzadeh, Aroona Cabra, Eshrat GharaeiFathabad, Fereshteh Pourmorad. Preparation of chitosan from Penicillium spp. And the determination of their degree of deacetylation. Indian J Biotechnol 2013;12:231-5.
23. Nadarajah K, Kader J, Mazmira M, Paul DC. Production of chitosan from fungi. Pak J Biol Sci 2001;4:263-5.

24. Paulino T, Simionato JI, Garcia JC, Nozaki J. Characterization of chitosan and chitin produced from silkworm chrysalides. Carbohydr Polym 2006;64:98-103.

25. Kasaai MR, Arul J, Charlet G. Intrinsic viscosity-molecular weight relationship for chitosan. J Polym Sci Part B: Polym Phys 2000;38:2591-8.

26. Adam Waskoa A, Piotr Bulakb, Magdalena Polak-Bereckaa, Katarzyna Nowakb, Cezary Polakowskib, Andrzej Bieganowski. The first report of the physicochemical structure of chitin isolated from Hermetiaillucens. Int J Biol Macromol 2016;92:316-20.

27. Suneeta Kumari, Pradip Kumar Rath. Extraction and characterization of chitin and chitosan from (Labeorohit) fish scales. Procedia Mater Sci 2014;6:482-9.

28. Erdogan S, Kaya M, Mol T, Baran T. Comparison of chitin structures isolated from seven Orthoptera species. Int J Biol Macromol 2015;72:797-805.

29. Helander I, Nurmiaho-Lassila E, Ahvenainen R, Rhoades J, Roller. Chitosan disrupts the barrier properties of the outer membrane of Gram-negative bacteria. Int J Food Microbiol 2001;71:235-44.

30. KAbu Tareq, Masihul Alam, Salim Raza, Tanvir Sarwar, Z Fardous, Alamgir Z Chowdhury, et al. Comparative study of antibacterial activity of chitin and chemically treated chitosan prepared from shrimp (Macrobrachium Rosenbergii) shell waste. J Virol Microbiol 2013:9. Doi:10.5171/2013.369217

\section{How to cite this article}

- Jesteena Johney, Kannan Eagappan, RR Ragunathan. Microbial extraction of chitin and chitosan from Pleurotus spp, its characterization and antimicrobial activity. Int J Curr Pharm Res 2017;9(1):88-93. 